\title{
A Look at the Diversity in Management of Respiratory Failure in Amyotrophic Lateral Sclerosis
}

In this issue of Respiratory Care, Sancho et $\mathrm{al}^{1}{ }^{\mathrm{de}}$ scribe a prospective study of medically stable subjects with amyotrophic lateral sclerosis (ALS) to determine possible clinical or functional predictors of need for noninvasive ventilation (NIV) during an acute lower respiratory tract infection. They used the criteria of the American College of Chest Physicians $^{2}$ to initiate NIV at home. The decision to initiate NIV has some variability, as previously cited in the literature. ${ }^{3}$ When analyzed with respect to current NIV guidelines, almost all subjects in the Sancho study ${ }^{1}$ should have been receiving NIV because they presented with an FVC of $<75 \%$ of predicted and a maximum inspiratory pressure of more than $-60 \mathrm{~cm} \mathrm{H}_{2} \mathrm{O}$. Some ALS centers currently consider, in addition to these criteria, the presence of signals/symptoms of respiratory insufficiency.

Sancho et al $^{1}$ describe an ALS population $(n=33)$ in which 23 subjects had spinal onset, and 10 subjects had bulbar onset. In the entire sample, 18 subjects did not require NIV during an acute respiratory infection. In this group $(n=18), 15$ subjects had spinal onset, and 3 subjects had bulbar onset. In a multivariate logistic regression analysis, however, the only variables that predicted the need for NIV $(n=15)$ were percent-of-predicted FVC (odds ratio of 1.06, 95\% CI 1.01-1.11) and peak cough flow (odds ratio of 2.57, 95\% CI 1.18-5.59). This informs the type of disease onset in patients with ALS that should be taken into account when we analyze predictors of the need for NIV. As the sample size was a limitation in this study, further research is necessary to validate these findings.

Another interesting aspect of this study was the use of mechanically assisted coughing, which was recommended when peak cough flow was $<4.25 \mathrm{~L} / \mathrm{s}$. However, it was not specified how many subjects who used the cough assist device were bulbar or spinal onset. Andersen et $\mathrm{al}^{4}$ investigated the effects of the cough assist device. They noted the presence of laryngeal dysfunction, which can compro-

Ms Braga has disclosed no conflicts of interest.

Correspondence: Translational and Clinical Physiology Unit, Molecular Medicine Institute, Faculty of Medicine, University of Lisbon, Avenida Professor Egas Moniz, 1649-028 Lisbon, Portugal. E-mail: carolineaero@hotmail.com

DOI: $10.4187 /$ respcare.04014 mise the effect of cough assist in patients with bulbar ALS, particularly in those with hypotonic bulbar paresis. Laryngeal adduction severely reduces the size of the laryngeal inlet, potentially with consequences for air flow and for the effects of cough assist. In these cases, we must consider whether invasive mechanical ventilation might be a better option to manage respiratory support and airway clearance.

See the Original Research on Page 492

The guidelines informing the decision to initiate NIV have been updated over the years. The main criteria, beyond percentof-predicted FVC, include: sniff nasal pressure, maximum inspiratory pressure, symptoms related to respiratory muscle weakness, nocturnal and diurnal desaturation and hypercapnia, and, more recently, phrenic nerve response. However, cultural and economic aspects still influence NIV use. .- $^{5}$

It should be remembered that, facing the option of managing respiratory insufficiency at home, caregivers are a very important part of ventilatory support. This is particularly true for patients with bulbar ALS who choose to receive invasive mechanical ventilation after NIV failure. In addition to ventilators, education regarding the proper use of other respiratory aids is required. Vianello et $\mathrm{al}^{9}$ suggested that administration of cough assist is effective and safely provided by trained nonprofessional caregivers and should be part of home management, where it can be used in combination with NIV to reduce the need for hospitalization. This might maintain a higher quality of life for a patient. However, conclusions from the revised report of the EFNS Task Force on ALS clinical management ${ }^{8}$ call attention to the point that managing mechanical ventilation for patients causes particular strain on caregivers, reducing their quality of life, raising their responsibilities related to managing the ventilator, and contributing to increasing care costs. Thus, we must be careful to evaluate the emotional, physical, and psychological capacity of a caregiver to deal with the increasing needs of a family member with ALS. Caregivers' quality of life and support for them can be seen as dependent variables with some weight in the success of NIV for patients with ALS. Future studies should consider this issue when assessing possible predictors of home NIV success or failure for patients with ALS.

Since the first years of NIV use, the number of NIV users in Europe and North America has increased. Unfortunately, 


\section{Managing Respiratory FaILURE IN ALS}

data from low-income countries are scarce. A motor neuron disease/ALS specialist/neurologist in a university hospital in the Western Cape province in South Africa (personal communication, 2014, Franclo Henning MD, Stellenbosch University, Cape Town, South Africa) summarized the main obstacles to NIV use in ALS: patients and families are often not aware of NIV, most patients are dependent on ALS support associations to supply equipment, NIV is often introduced at a late stage due to lack of specialized ALS care that would ensure early identification of respiratory failure, lack of access to power supply for patients in poor communities excludes them from NIV use, and cost often limits access to only basic systems that do not include humidification and different interfaces to improve adherence. All these factors contrast with the reality described in the trials performed in more developed countries. Some European countries use telemonitoring for follow-up of patients with ALS on NIV. The association of distance monitoring with more efficient portable ventilators may at first give the impression that this is more costly for health systems and their users. There have been some studies on the cost-benefit relationship developed in European countries. ${ }^{10,11}$ Pinto et al ${ }^{12}$ showed that the investment per year for hospitals to implement is not significant with attenuation of this cost in medium-term and that this model of care promotes a better allocation of available health resources, avoids unnecessary visits to specialized centers, and may have impact on hospital readmissions. Health-care models in which it is possible to combine technology with patient-centered care may have direct impact on non-medical costs, such as wages lost due to caregiver absenteeism, and also financial and personal costs, such as unnecessary visits to urgent care. Future studies must realize the impact of telemonitoring on the cost of health services, as well as on hospital readmissions and caregivers.

Anna Caroline Marques Braga MSc PT Translational and Clinical Physiology Unit Molecular Medicine Institute Faculty of Medicine University of Lisbon Lisbon, Portugal

\section{REFERENCES}

1. Sancho J, Servera E, Bañuls P, Marin J. Predictors of need for noninvasive ventilation during respiratory tract infections in medically stable, non-ventilated patients with amyotrophic lateral sclerosis. Respir Care 2015;60(4):492-497.

2. Consensus Conference Report. Clinical indications for noninvasive positive pressure ventilation in chronic respiratory failure due to restrictive lung disease, COPD and nocturnal hypoventilation. Chest 1999;116(2):521-534.

3. Radunović A, Mitsumoto H, Leigh PN. Clinical care of patients with amyotrophic lateral sclerosis. Lancet Neurol 2007;6(10):913-925.

4. Andersen T, Sandnes A, Hilland M, Halvorsen T, Fondenes O, Heimdal JH, et al. Laryngeal response patterns to mechanical insufflationexsufflation in healthy subjects. Am J Phys Med Rehabil 2013; 92(10):920-929.

5. Chetta A, Aiello M, Tzani P, Olivieri D. Assessment and monitoring of ventilator function and cough efficacy in patients with amyotrophic lateral sclerosis. Monaldi Arch Chest Dis 2007;67(1):43-52.

6. National Institute for Health and Care Excellence. Motor neurone disease: the use of non-invasive ventilation in the management of motor neuron disease. http://www.nice.org.uk/nicemedia/pdf/ CG105NICEguideline.pdf. Accessed November 28, 2014.

7. Rabec C, Rodenstein D, Leger P, Rouault S, Perrin C, GonzalezBermejo J, SomnoNIV Group. Ventilator modes and settings during non-invasive ventilation: effects on respiratory events and implications for their identification. Thorax 2011;66(2):170-178.

8. EFNS Task Force on Diagnosis and Management of Amyotrophic Lateral Sclerosis, Andersen PM, Abrahams S, Borasio GD, de Carvalho $\mathrm{M}$, Chio A, et al. EFNS guidelines on the clinical management of amyotrophic lateral sclerosis (MALS)-revised report of an EFNS task force. Eur J Neurol 2012;19(3):360-375.

9. Vianello A, Corrado A, Arcaro G, Gallan F, Ori C, Minuzzo M, Bevilacqua M. Mechanical insufflation-exsufflation improves outcomes for neuromuscular disease patients with respiratory tract infections. Am J Phys Med Rehabil 2005;84(2):83-88; discussion 8991.

10. Vitacca M, Bianchi L, Guerra A, Fracchia C, Spanevello A, Balbi B, Scalvini S. Tele-assistance in chronic respiratory failure patients: a randomised clinical trial. Eur Respir J 2009;33(2):411-418.

11. Lopes de Almeida JP, Pinto A, Pinto S, Ohana B, de Carvalho M. Economic cost of home-telemonitoring care for BiPAP-assisted ALS individuals. Amyotrop Lateral Scler 2012;13(6):533-537.

12. Pinto A, Almeida JP, Pinto S, Pereira J, Oliveira AG, de Carvalho M. Home telemonitoring of non-invasive ventilation decreases healthcare utilization in a prospective controlled trial of patients with amyotrophic lateral sclerosis. J Neurol Neurosurg Psychiatry 2010;81(11): 1238-1242. 